\title{
Intrastriatal injection of a-synuclein can lead to widespread synucleinopathy independent of neuroanatomic connectivity
}

Zachary A. Sorrentino ${ }^{1,2}$, Mieu M.T. Brooks ${ }^{1,2,4}$, Vincent Hudson III ${ }^{1,2}$, Nicola J. Rutherford ${ }^{1,2}$, Todd E. Golde ${ }^{1,2,3}$, Benoit I. Giasson ${ }^{1,2,3^{*}}$ and Paramita Chakrabarty ${ }^{1,2,3^{*}}$

\begin{abstract}
Background: Prionoid transmission of a-synuclein (aSyn) aggregates along neuroanatomically connected projections is posited to underlie disease progression in a-synucleinopathies. Here, we specifically wanted to study whether this prionoid progression occurs via direct inter-neuronal transfer and, if so, would intrastriatal injection of aSyn aggregates lead to nigral degeneration.

Methods: To test prionoid transmission of aSyn aggregates along the nigro-striatal pathway, we injected amyloidogenic aSyn aggregates into two different regions of the striatum of adult human wild type aSyn transgenic mice (Line M20) or non-transgenic (NTG) mice and aged for 4 months.

Results: M20 mice injected in internal capsule (IC) or caudate putamen (CPu) regions of the striatum showed florid aSyn inclusion pathology distributed throughout the neuraxis, irrespective of anatomic connectivity. These aSyn inclusions were found in different cell types including neurons, astrocytes and even ependymal cells. On the other hand, intrastriatal injection of aSyn fibrils into NTG mice resulted in sparse aSyn pathology, mostly localized in the striatum and entorhinal cortex. Interestingly, NTG mice injected with preformed human aSyn fibrils showed no induction of aSyn inclusion pathology, suggesting the presence of a species barrier for aSyn fibrillar seeds. Modest levels of nigral dopaminergic (DA) neuronal loss was observed exclusively in substantia nigra (SN) of M20 cohorts injected in the IC, even in the absence of frank aSyn inclusions in DA neurons. None of the NTG mice or CPu-injected M20 mice showed DA neurodegeneration. Interestingly, the pattern and distribution of induced aSyn pathology corresponded with neuroinflammation especially in the SN of M20 cohorts. Hypermorphic reactive astrocytes laden with aSyn inclusions were abundantly present in the brains of M20 mice.

Conclusions: Overall, our findings show that the pattern and extent of dissemination of aSyn pathology does not necessarily follow expected neuroanatomic connectivity. Further, the presence of intra-astrocytic aSyn pathology implies that glial cells participate in aSyn transmission and possibly have a role in non-cell autonomous disease modification.
\end{abstract}

Keywords: a-synuclein, Amyloid, Prion, Striatum, Dopaminergic Neurodegeneration, Astrocyte

\footnotetext{
* Correspondence: bgiasson@ufl.edu; pchakrabarty@ufl.edu

'Department of Neuroscience, University of Florida, 1275 Center Drive, PO

Box 100159, Gainesville, FL 32610, USA

Full list of author information is available at the end of the article
} 


\section{Background}

Intracellular accumulation of misfolded $\alpha$-synuclein ( $\alpha$ Syn $)$ is a neuropathological hallmark of $\alpha$-synucleinopathies [1-3]. Inclusions comprised of amyloidogenic $\alpha$ Syn aggregates, phosphorylated at Serine129 [4-6] are often found in neuronal cell bodies termed Lewy bodies (LB) or in neuronal projections, called Lewy neurites [1-3]. Nevertheless, how $\alpha$ Syn pathology initiates and spreads in the nervous system is still an area of intense research and debate.

In recent years, prion-like conformational templating has emerged as a plausible major mechanism that may explain the stereotypic progression of pathogenic $\alpha$ Syn into different brain regions [7-10]. Cell culture studies have shown that endogenous $\alpha$ Syn can be conformationally altered in the presence of exogenous pathologic $\alpha$ Syn to aggregate into inclusions [11-14], akin to classical prions [15, 16]. In vivo evidence for this prion-like characteristic of $\alpha$ Syn pathogenesis emerged from studies involving direct intracerebral injections of preformed $\alpha$ Syn amyloid fibrils in $\alpha$ Syn transgenic mice $[17,18]$. More recently, studies have shown that peripheral (intramuscular, intraperitoneal or intravenous) injections of $\alpha$ Syn amyloid fibrils into rodents can induce progressive formation of $\alpha$ Syn pathology in the CNS [19-22]. However, the extent of induction and spread of seeded $\alpha$ Syn pathology in wild type nontransgenic (NTG) mice brains, on the other hand is more disparate; for example, while our group has observed that molecular templating and dissemination of pathogenic $\alpha$ Syn is an imprecise event in NTG mice [23], others have reported robust and widespread $\alpha$ Syn pathologies following exogenous $\alpha$ Syn challenge in NTG mice [14, 24-26]. Interestingly, injecting different molecular strains of $\alpha$ Syn can result in distinctive pathologies in rodents, possibly reflective of the spectrum of disease pathologies seen in different types of $\alpha$ synucleinopathies $[20,27,28]$. Such dependence of seeded pathology on the presence of distinct conformer strains has been shown to exist in classical prion diseases [29]. Overall, these studies have established that $\alpha$ Syn can spread in the CNS by prion-like templating mechanisms [7-10].

Several recent publications have reported that following intracerebral injection of preformed $\alpha$ Syn fibrils, induction of intra-neuronal $\alpha$ Syn pathology leads to neurodegeneration, especially in the dopaminergic (DA) neurons of the nigrostriatal pathway $[20,24,30]$. This is reminiscent of selective neurodegeneration in $\alpha$-synucleinopathies, such as Parkinson's disease [31]. Understanding how intercellular transmission of pathological $\alpha$ Syn along specific neuroanatomic projections leads to selective neurodegeneration in Parkinsonisms and related Lewy body dementias will allow us to design better therapeutics against these diseases. To test whether intrastriatal injection of pathological $\alpha$ Syn aggregates leads to selective nigral degeneration and further whether this is dependent on overexpression of human $\alpha$ Syn transgene, we administered preformed $\alpha$ Syn aggregates into the internal capsule (IC) or the caudate putamen $(\mathrm{CPu})$ areas of either Line M20 (transgenic mice expressing human wild type (WT) $\alpha$ Syn [32]) or NTG mice. Our results indicate that while induction of $\alpha$ Syn pathology was sparse in NTG mice, M20 mice showed extensive Lewy-type inclusion pathology widely distributed throughout the brain, irrespective of anatomic connectivity. Surprisingly, we did not observe any $\alpha$ Syn inclusion pathology in DA neurons and only modest levels of DA neurodegeneration were noticed in M20 mice injected in the IC. We observed induction of gliosis that is associated with incipient $\alpha$ Syn pathology and interestingly, massive levels of pathological $\alpha$ Syn inclusions were detected within astrocytes in M20 mice. Overall, our results suggest that a combination of glial and neuronal inclusion pathology may result in distinctive $\alpha$ Syn strains that display widespread patterns of dissipation throughout the CNS without obvious direct neuroanatomic connectivity.

\section{Methods \\ Expression and purification of recombinant aSyn protein}

The bacterial expression plasmid pRK172 cDNA construct encoding full-length WT human or mouse $\alpha$ Syn was used to express these proteins in E. coli BL21 (DE3) and they were purified to homogeneity by size exclusion (Superdex 200 gel filtration) followed by ion exchange (Mono Q) chromatographies as previously described [33].

\section{Fibril preparation of recombinant aSyn for mouse brain injection}

Human $\alpha$ Syn recombinant protein or mouse $\alpha$ Syn recombinant protein was assembled into filaments by incubation at $37{ }^{\circ} \mathrm{C}$ at $5 \mathrm{mg} / \mathrm{ml}$ in sterile PBS (Invitrogen) with continuous shaking at $1050 \mathrm{rpm}$ (Thermomixer R, Eppendorf, Westbury, NY). $\alpha$ Syn amyloid fibril assembly was monitored as previously described with K114 fluorometry [12]. $\alpha$ Syn fibrils were diluted to a concentration of $2 \mathrm{mg} / \mathrm{mL}$ in sterile PBS and gently sonicated at room temperature in a water bath sonicator for $1 \mathrm{~h}$. This resulted in fragmentation of $\alpha$ Syn amyloid aggregates into shorter fibrils [17, 22]. These fibrils were imaged using transmission electron microscopy (EM) (Additional file 1: Figure S1), and were validated for induction of intracellular amyloid inclusion formation in cell culture as previously described [12]. For EM imaging, fibrils were adsorbed to 300-mesh carboncoated copper grids, washed, stained with $1 \%$ uranyl acetate, and imaged at 100,000 × magnification using a Hitachi H7600 transmission electron microscope (Hitachi).

\section{Mouse husbandry and stereotactic injections}

All procedures were performed according to the $\mathrm{NIH}$ Guide for the Care and Use of Experimental Animals and were approved by the University of Florida Institutional Animal Care and Use Committee. Line M20 mice 
express human WT $\alpha$ Syn and do not develop any intrinsic phenotype or $\alpha$ Syn pathology [32]. 2 months old M20 or NTG mice were bilaterally injected with $2 \mu \mathrm{l}$ of $2 \mathrm{mg} / \mathrm{ml}$ human or mouse WT $\alpha$ Syn fibrils in the IC (coordinates from Bregma: A/P -0.5, L +/-1.5, D/V -3.0; Cohorts 1, 2, 4 and 5) or $\mathrm{CPu}$ (coordinates from Bregma: $\mathrm{A} / \mathrm{P}+0.5, \mathrm{~L}+/-2.0, \mathrm{D} / \mathrm{V}-3.5$; Cohort 3 and Cohort 6). The inoculum was injected at a rate of $0.2 \mu \mathrm{l}$ per min with the needle in place for $15 \mathrm{~min}$ at each site. Mice were analyzed 4-5 months following injection. Cohort sizes are described in Figs. 1 and 3.

\section{Antibodies}

The following antibodies were used to detect pathological $\alpha$ Syn phosphorylated at Ser129: 81A (B. Giasson; 1:10,000 for immunohistochemistry and 1:3000 for immunofluorescence; [5]) and EP1536Y (1:1000; AbCam, Cambridge, MA). The latter antibody specifically reacts with pSer129$\alpha$ Syn and does not cross-react with phosphorylated lowmolecular-mass neurofilament subunit [7]. Other antibodies used in this study are: Syn506, a conformation specific anti- $\alpha$ Syn antibody that preferentially detects $\alpha$ Syn in pathological inclusions (B. Giasson; 1:1000; [34]); anti-p62/sequestosome antibody (SQSTM1) (Proteintech, Chicago, IL); anti-glial fibrillary acidic protein (GFAP) (Dako, Carpentaria, CA); anti-Iba-1 antibody (1:1000; Wako, Richmond, VA) and anti-tyrosine hydroxylase (TH) antibody (Millipore, Billerica, MA).

\section{Immunohistochemical and immunofluorescence analyses}

Mouse brains and spinal cords were collected following intra-cardiac perfusion with $\mathrm{PBS} /$ heparin. Tissues were fixed with $70 \%$ ethanol/150 mM NaCl for $48 \mathrm{~h}$ followed by paraffin processing. Paraffin-embedded tissue sections were deparaffinized and hydrated through a series of graded ethanol solutions followed by washing with $0.1 \mathrm{M}$ Tris, $\mathrm{pH}$ 7.6. The sections were blocked with $2 \% \mathrm{FBS}$ in $0.1 \mathrm{M}$ Tris, $\mathrm{pH}$ 7.6. Immunohistochemical detection was done using avidin-biotin complex $(\mathrm{ABC})$ system (Vectastain $\mathrm{ABC}$ Elite Kit, Vector Laboratories, Burlingame, $\mathrm{CA}$ ) and immunocomplexes were visualized with the chromogen 3,3'-diaminobenzidine (DAB). Sections were counterstained with hematoxylin. Slides were scanned using an Aperio ScanScope CS (Aperio Technologies Inc., Vista, CA) and images acquired using the ImageScopeTM software (Aperio Technologies Inc.). Quantification of immunostaining was done using the Pixel count Program (ImageScope, Aperio Technologies). For immunofluorescence detection, sections were incubated with secondary antibodies conjugated to Alexa fluor 594 or Alexa fluor 488 (Invitrogen, Eugene, OR) followed by Sudan Black treatment and staining with DAPI (Invitrogen, Eugene, OR). The sections were coverslipped with Fluoromount-G (Southern Biotech, Birmingham, AL) and visualized using an Olympus BX51 microscope mounted with a DP71 Olympus digital camera.

\section{Stereological analysis of TH neurons in the substantia nigra TH-positive neurons in the substantia nigra (SN) were counted by staining paraffin-embedded sections with an anti-TH polyclonal antibody (Millipore, Billerica, MA). Ste- reological counting of DA neurons was performed by count- ing and tallying $\mathrm{TH}$-immunopositive neurons on every tenth section based on a previously published report [35].}

\section{Results}

Induction and spread of pathological aSyn in M20 mice does not strictly follow neuroanatomic projections

To test the idea that induction of $\alpha$ Syn pathology follows pre-determined neuroanatomic pathways, we injected

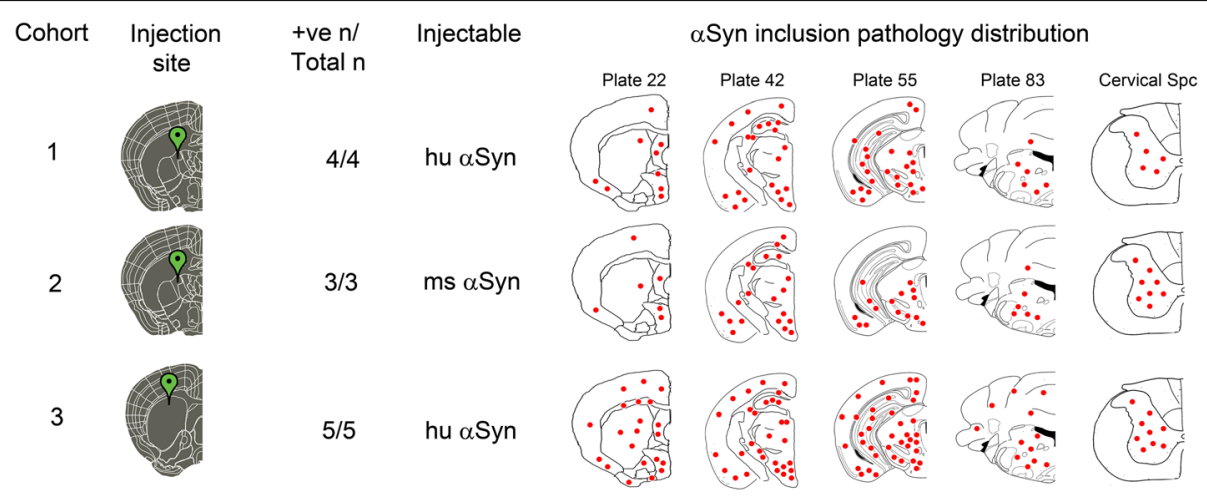

Fig. 1 Summary of distribution of aSyn pathology in Line M20 mice following intrastriatal injection of human or mouse aSyn fibrils. In Cohorts 1 and 2, mice were injected with human (hu) WT aSyn fibrils (Cohort 1) or mouse (ms) WT aSyn fibrils (Cohort 2) in the IC area whereas Cohort 3 mice were injected with human WT aSyn fibrils in the CPu. The total number of mice injected in each cohort as well as the number of mice actually displaying aSyn pathology is depicted (denoted as +ve $\mathrm{n} /$ Total $\mathrm{n}$ ). Rostro-caudal distribution of aSyn inclusions is presented on a schematic brain and spinal cord map, with red dots depicting the relative abundance of aSyn inclusions in different brain and spinal cord locations. The numbers on top of the brain map schematics correspond to plates from the Paxinos Brain Atlas [57] 
aggregated WT $\alpha$ Syn fibrils in two distinct regions of the striatum of 2 month old line M20 mice that overexpress human WT $\alpha$ Syn [32] as well as their NTG littermates. The M20 mice never intrinsically develop $\alpha$ Syn inclusion pathology or have overt phenotypes [32]. These injections were done to enable us to (1) study the efficiency of templated induction of WT $\alpha$ Syn pathology and (2) further conduct studies in NTG mice that are much less inherently susceptible to induction of $\alpha$ Syn inclusion pathology [23] so that we could better visualize and interpret frank transmission occurring via neuroanatomic connectivity. Cohorts 1 and 2 of M20 mice received bilateral injections into the IC while the Cohort 3 received bilateral injections in the $\mathrm{CPu}$ (Fig. 1). The IC, containing myelinated corticospinal tracts, intersects the caudate nucleus and putamen of the striatum. It serves as a conduit between motor areas, frontopontine, and thalamic peduncles to brain stem and cerebellar regions, and also between the thalamus and prefrontal cortex. Examination of Cohort 1 injected with human $\alpha$ Syn fibrils (Figs. 1 and 2a) or Cohort 2 injected with mouse $\alpha$ Syn fibrils (Figs. 1 and $2 b$ ) showed similar distribution of pSer129 $\alpha$ Syn/81A-immunopositive pathologies. $\alpha$ Syn pathology was further confirmed by staining sections with an additional antibody against pSer129- $\alpha$ Syn (EP1536Y) as well as an antibody raised against conformationally altered $\alpha$ Syn (Syn506). Immunostaining with p62/sequestosome confirmed that the intraneuronal and neuritic $\alpha$ Syn staining represented frank inclusion pathology (Fig. 2a-b). In both cohorts, robust $\alpha$ Syn inclusion pathology was found spread over multiple neuroanatomically connected areas as well as other areas of the brain that have no known direct connections to the IC. Overall, human $\alpha$ Syn fibril injected M20 mice (Cohort 1) showed profuse $\alpha$ Syn pathology in motor cortex, piriform cortex, somatosensory cortex, amygdala (basolateral and basomedial nuclei), ventral thalamus, IC, hypothalamus (ventromedial and dorsomedial), hippocampus, dentate gyrus, retrosplenial cortex, geniculate nucleus, SN region, retromammillary body, posterior commissure, cerebellar folia, vestibular nuclei and spinal cord (Figs. 1 and 2a, Additional file 2: Figure S2). Surprisingly, we observed very limited $\alpha$ Syn pathology in the CPu region. In M20 mice injected with mouse $\alpha$ Syn fibrils (Cohort 2), $\alpha$ Syn pathology was observed in all of these areas except there was sparse to no pathology in somatosensory cortex and retrosplenial cortex (Figs. 1 and $2 \mathrm{~b}$, Additional file 2: Figure S2). On the whole, this data shows that the induction and subsequent dissemination of the template $\alpha$ Syn pathology in M20 mice is widespread and not strictly restricted to areas that are neuroanatomically connected to the IC.

Since the IC provides connectivity between various brain areas supporting multiple, diverse, and dissociable functional regions, we next investigated whether injecting human $\alpha$ Syn fibrils directly into the $\mathrm{CPu}$ resulted in transmission of induced $\alpha$ Syn pathology into discrete areas linked by direct projections from this area (Cohort 3). The $\mathrm{CPu}$ area receives inputs from the cortex and sends projections directly into the globus pallidus, thalamus, and $\mathrm{SN}$. Mice were examined for $\alpha$ Syn inclusion pathology following injection of human $\alpha$ Syn fibrils into the $\mathrm{CPu}$. These M20 mice showed essentially a similar distribution of $\alpha$ Syn pathology as observed in Cohort 1 and Cohort 2 mice (Figs. 1 and 2c), indicating that templated induction of $\alpha$ Syn pathology follows similar patterns of distribution whether initiated in a white matter enriched area (IC) or a projection rich area $(\mathrm{CPu})$. All M20 cohorts (Cohorts 1, 2 and 3) showed extensive perikaryal as well as axonal pathology; additionally, Cohort 3 mice showed pathology throughout the cortex especially in the visual and entorhinal cortex (Figs. 1 and 2c, Additional file 2: S2). On the whole, Cohort 3 of M20 mice showed relatively more robust and widespread distribution of $\alpha$ Syn inclusion pathology than mice injected with human $\alpha$ Syn fibrils or mouse $\alpha$ Syn fibrils in the IC (Cohorts 1, 2) (Fig. 2a-c). An important distinction between these cohorts is that the Cohort 3 mice seemed to develop relatively more robust $\alpha$ Syn pathology in and around the area of injection, i.e., striatum, than Cohort 1 and 2 mice, which had limited $\alpha$ Syn pathology proximal to the area of injection. We also observed robust induction of $\alpha$ Syn inclusion pathology in the ependymal cells abutting the lateral ventricles in the human $\alpha$ Syn fibril injected M20 mice in Cohorts 1 and 3 (Additional file 3: Figure S3).

\section{Induction and spread of pathological aSyn in NTG mice is sparse and restricted}

In our previous studies, we found that following intrahippocampal seeding, the templated induction of $\alpha$ Syn pathology in NTG mice is a relatively inefficient process compared to $\alpha$ Syn transgenic M20 mice [17, 23]. We reasoned that if there was any frank propagation of pathology along neuroanatomic connections, we would be able to clearly visualize this phenomenon in NTG mice that otherwise do not develop a surfeit of $\alpha$ Syn pathology outside of the area of injection. To characterize propagation of conformationally altered $\alpha$ Syn in NTG mice, we injected mouse $\alpha$ Syn fibrils (Cohort 4) or human $\alpha$ Syn fibrils (Cohort 5) into the IC (Figs. 3 and 4a) or mouse $\alpha$ Syn fibrils in the CPu (Cohort 6) (Figs. 3 and 4b). Cohort 5 had no detectable $\alpha$ Syn pathology and therefore no further analysis was done in these mice (data not shown). We noticed that in Cohorts 4 and 6, $\alpha$ Syn inclusion pathology was observed in dorsal striatum $(\mathrm{CPu})$, thalamus, piriform cortex and entorhinal cortex (Figs. 3 and 4). Mice injected in the IC did not show appreciable $\alpha$ Syn pathology in the motor cortex, which is unexpected 


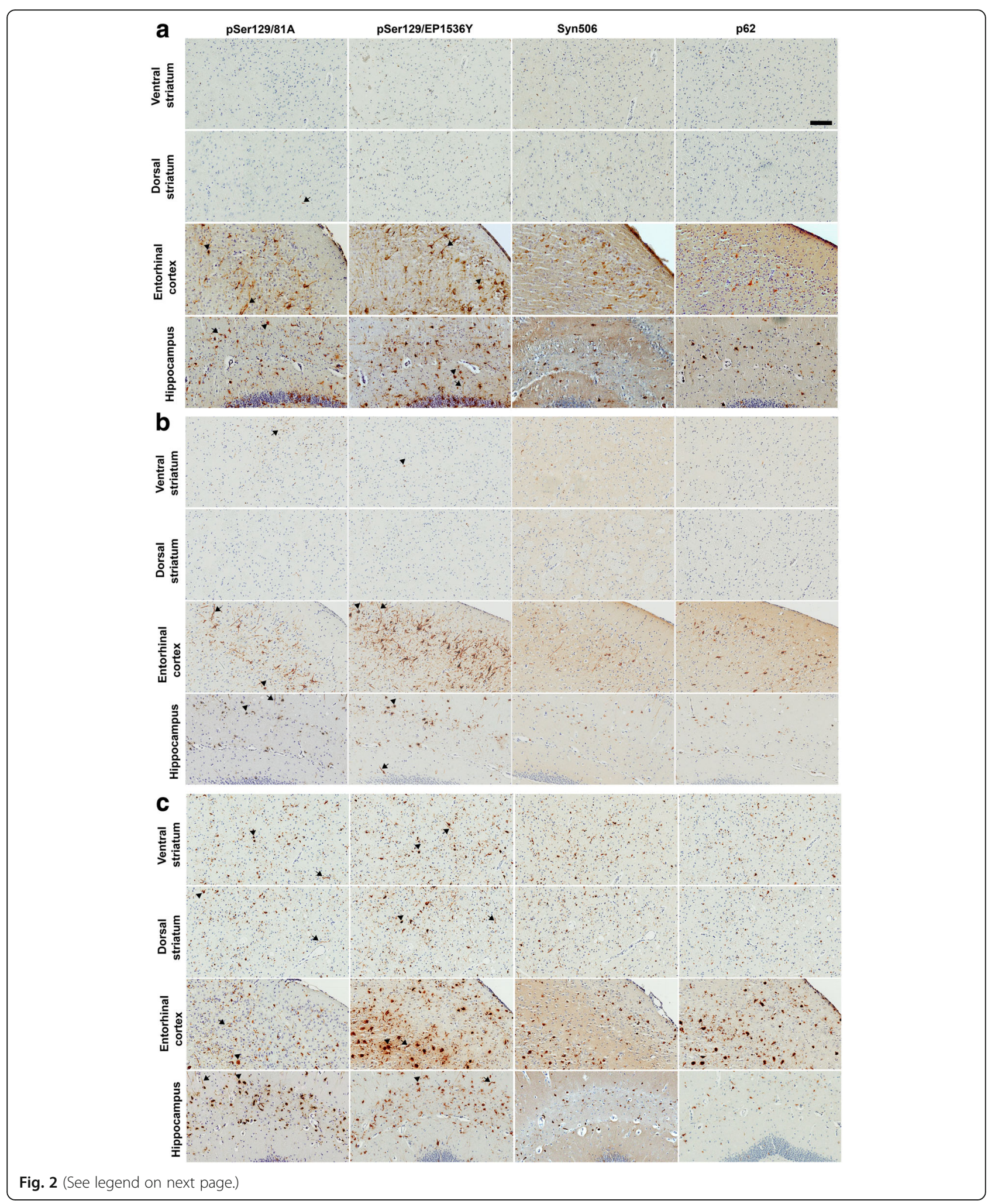


(See figure on previous page.)

Fig. 2 Induction of aSyn pathology following injection of aSyn fibrils in the IC of line M20 mice. 2 month old Line M20 mice were injected with pre-formed human WT aSyn fibrils in IC (a, Cohort 1) or mouse WT aSyn fibrils in IC (b, Cohort 2) or human WT aSyn fibrils in the CPu (c, Cohort 3) and analyzed after 4 months. Abundant aSyn inclusion pathology, detected by pSer129-aSyn antibodies (81A and EP1536Y) was observed in most areas of the brain, even those that are not directly connected to the striatum, such as the hippocampus. Surprisingly, areas adjacent to the IC, such as the ventral and dorsal striatum had few pathological inclusions. Inclusion pathology was confirmed using a conformation-specific antibody against aSyn, Syn506, and p62/Sqstm1 antibody, which is a well-established marker of cytoplasmic LB inclusions. Both perikaryal (arrowhead) and neuritic (arrow) aSyn pathology were observed. The relative distribution and abundance of aSyn pathology in Cohort 3 was similar to Cohort 1, except that mice in Cohort 3 had relatively higher density of aSyn inclusion pathology in the striatum. Note that since 1 mouse in Cohort 2 died prematurely from hindlimb paralysis, neuropathological analysis could not be performed. Scale Bar, $100 \mu m ; n=3-5$ mice

given that the IC is richly populated by corticospinal tracts (Figs. 3 and 4b). In both of these cohorts of NTG mice, the majority of the $\alpha$ Syn inclusions were perikaryal, with limited neuritic pathology (Fig. 4). Neither of these two cohorts showed any appreciable $\alpha$ Syn pathology in other areas that are neuroanatomically connected to the striatum, e.g., thalamus and SN region. Additionally, we did not observe any $\alpha$ Syn pathology in ependymal cells (Additional file 3: Figure S3), cerebellum or spinal cord (data not shown) of NTG mice.

Intra-striatal administration of aSyn aggregates does not necessarily induce degeneration of dopaminergic neurons in the substantia nigra

Tractographic studies have conclusively established that striatal neurons (both dorsal and ventral) project monosynaptically to DA neurons in the SN [36]. Especially, a majority of projections from the posterior aspect of the striatum has been shown to lead into the DA neurons of $\mathrm{SN}$ and retrorubral nucleus [37]. Therefore, we expected that direct injections of $\alpha$ Syn fibrils into the dorsal striatum $(\mathrm{CPu})$ or IC (situated between caudate and putamen) should result in targeting DA neurons in the $\mathrm{SN}$. Though we observed pSer129 $\alpha$ Syn immunopositive inclusions in the SN region and striatum of M20 transgenic mice, the $\alpha$ Syn inclusion pathology did not co-localize with the TH-immunopositive DA neuronal cell bodies (Additional file 4: Figure S4). We then conducted stereologic counting of TH-immunopositive DA neurons in M20 (Cohorts 1-3) or NTG mice (Cohorts 4-6) to explore whether seeded $\alpha$ Syn pathology affects survival of DA neurons in the $\mathrm{SN}$. We observed a modest reduction in number of DA neurons in M20 transgenic mice injected in the IC with human $\alpha$ Syn fibrils $(\downarrow 25.5 \%$; Cohort 1 ) or mouse $\alpha$ Syn fibrils $(\downarrow 20.6 \%$; Cohort 2$)$ (Fig. 5). Surprisingly, M20 transgenic mice injected with human $\alpha$ Syn fibrils in the $\mathrm{CPu}$ (Cohort 3) did not show any DA neuronal loss (Fig. 5). None of the NTG mice injected with either human $\alpha$ Syn fibrils (Cohort 5) or mouse $\alpha$ Syn fibrils (Cohorts 4 and 6 ) showed any nigral neuronal loss (Fig. 6).

\section{Characterization of astrocytosis and microgliosis in aSyn seeded mice}

To understand how gliosis is altered in $\alpha$ Syn seeded milieus, we conducted region-wise analysis of astrocytes and microglia in M20 and NTG mice. Overall, the induction of astrogliosis was much more consistently reproducible in $\mathrm{M} 20$ mice injected in the $\mathrm{CPu}$ (Cohort 3) compared to all other cohorts. In M20 mice, injection in $\mathrm{CPu}$ with human $\alpha$ Syn fibrils (Cohort 3) resulted in the most striking and consistent increases in astrocytosis

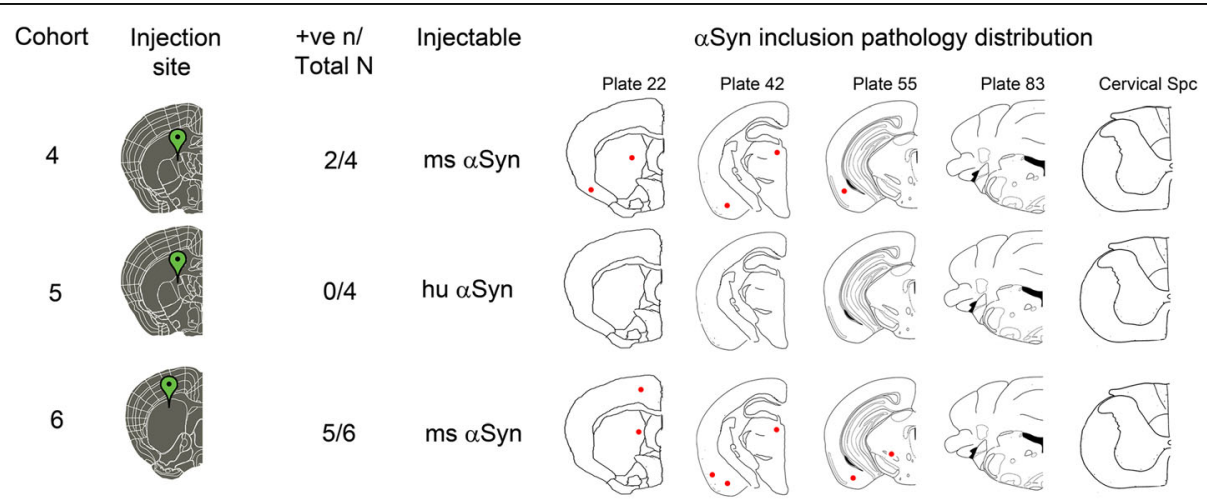

Fig. 3 Summary of distribution of aSyn pathology in NTG mice following intrastriatal injection of human or mouse aSyn fibrils. NTG mice were injected with mouse WT aSyn fibrils (Cohort 4) or human WT aSyn fibrils (Cohort 5) in the IC area whereas Cohort 6 mice were injected with mouse WT aSyn fibrils into the CPu. The total number of mice in each cohort as well as the number of mice displaying induced aSyn pathology is shown (denoted as +ve $n / T o t a l n$ ). Rostro-caudal distribution of inclusions is presented on schematic brain maps, with red dots depicting the relative abundance of aSyn inclusions in different brain and spinal cord locations. The numbers on top of the brain schematic correspond to plates from the Paxinos Brain Atlas [57] 


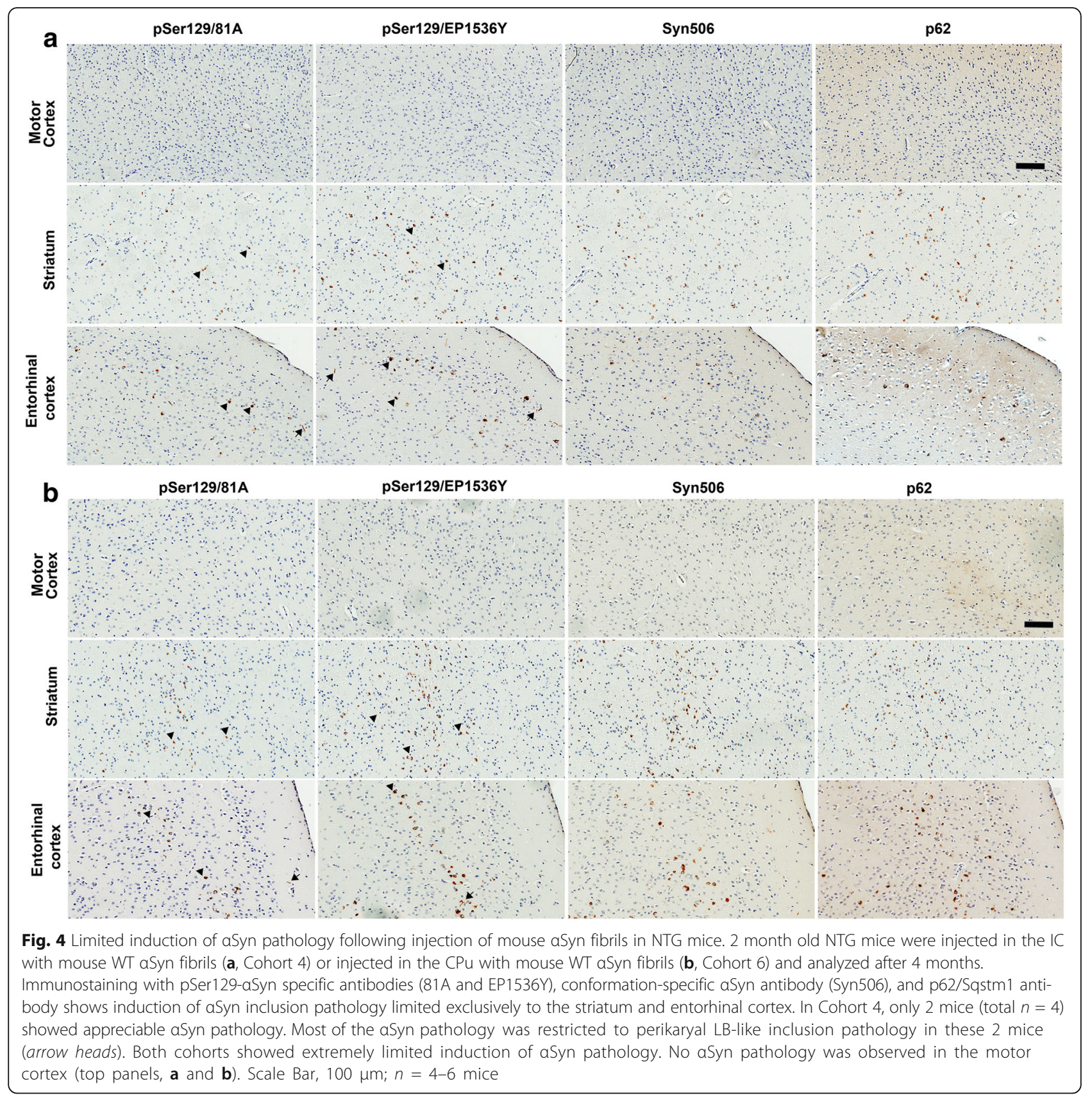

(GFAP immunostaining) (Fig. 7a) and microgliosis (Iba-1 immunostaining) (Fig. 7c) in the striatum. Other areas distal to the injection sites that displayed robust $\alpha$ Syn deposits in these mice, such as the hippocampus and entorhinal cortex, also showed increased GFAP and Iba-1 staining, albeit with more individual variability compared to striatum (Additional file 5: Figure S5, Fig. 7a and c).

Line M20 mice injected in IC (Cohorts 1 and 2) showed much more variability in astrogliosis across individual mice, in spite of consistently uniform distribution of $\alpha$ Syn pathology in these mice. In particular, Cohort 1 mice showed no induction of gliosis in and around the area of injection (i.e., striatum) (Fig. 7a), whereas there was increased astrogliosis and microgliosis in hippocampus and entorhinal cortex, albeit with more mouse-tomouse variability; therefore, in a facile sense, induction of astrogliosis cannot be directly explained by the accretion of induced $\alpha$ Syn pathology (Additional file 5: Figure S5). Interestingly, there is also discordance between GFAP and Iba-1 immunostaining that is strikingly evident in the M20 mice injected in the IC (Cohorts 1 and 2) - for example, there was generally higher levels of astrogliosis in Cohort 2 compared to limited alterations in microgliosis (Fig. 7a and c; Additional file 5: Figure S5). 

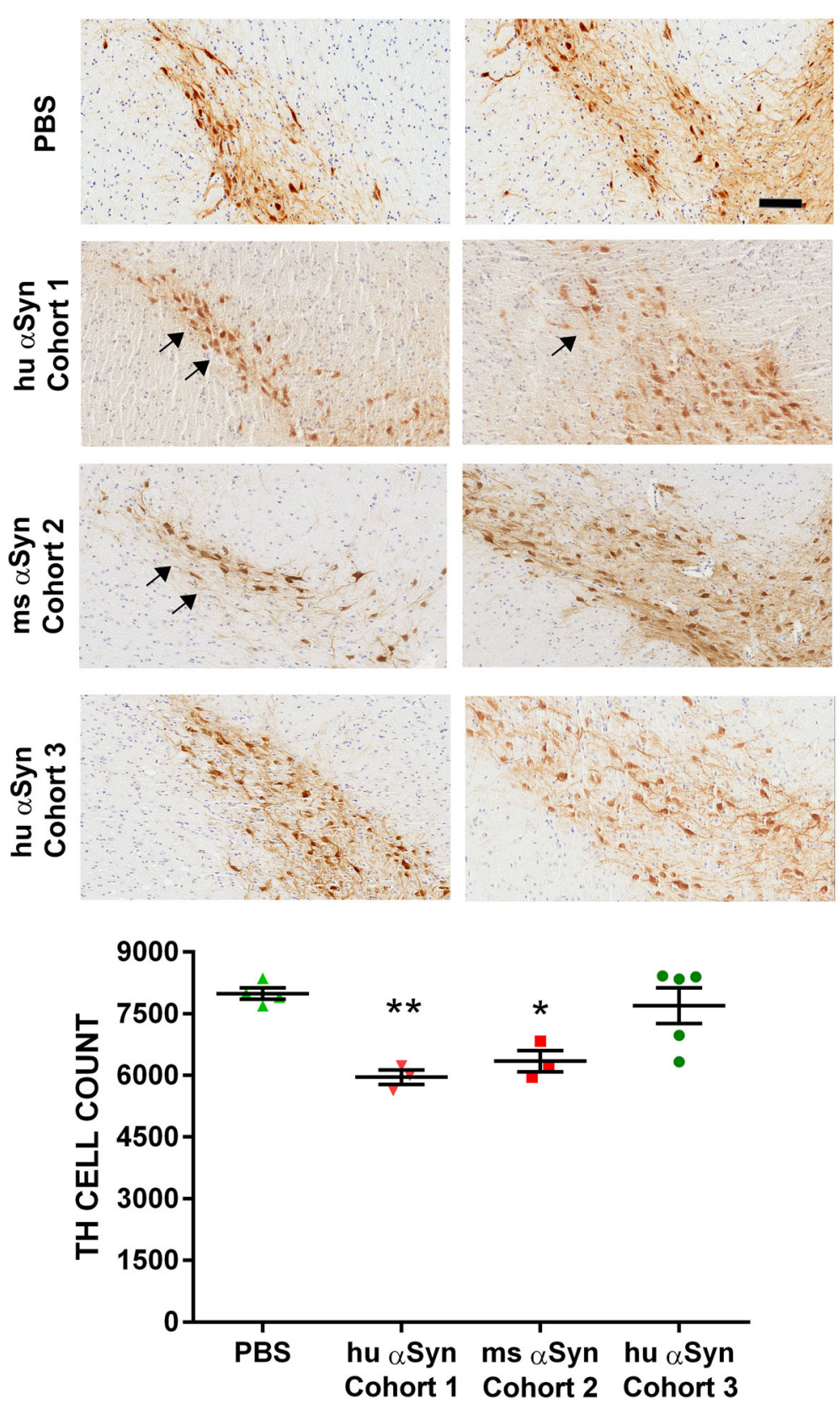

Fig. 5 Modest levels of nigral DA neuronal loss in line M20 mice injected in IC with aSyn fibrils. Line M20 mice were injected in the IC (Cohorts 1 and 2) or CPu (Cohort 3) with WT aSyn fibrils. Representative TH staining depicting SN-resident DA neurons in the dorsal (left panel) and ventral aspects (right panel) are shown. Mice that were injected with either human aSyn fibrils (Cohort 1) or mouse aSyn fibrils (Cohort 2) showed modest levels of DA degeneration as determined by counting TH-immunostained neurons in the SN ( 20-25\% compared to PBS injected control mice). The thinning of the nigral TH neuron layer is indicated by arrows. Cohort 3 mice injected with human aSyn fibrils did not display any nigral degeneration. PBS injected Line M20 mice were considered as control group for all cohorts. Scale Bar, $100 \mu \mathrm{m} ; n=3-5 /$ cohort. One way Anova, ${ }^{* *} p<0.01$, ${ }^{*} p<0.5$

The extent of astrogliosis and microgliosis in NTG mice was variable throughout brain regions in the $\alpha$ Syn injected cohorts. Overall, in NTG mice injected in the IC (Cohorts 4 and 5) or $\mathrm{CPu}$ (Cohort 6), we observed sparse astrogliosis (Fig. 7b and d, Additional file 6: Figure S6). For example, Cohort 5 of NTG mice with no induction of $\alpha$ Syn inclusion pathology (i.e., injected in IC with human $\alpha$ Syn fibrils) expectedly does not show increased astrogliosis. Interestingly, with respect to mouse $\alpha$ Syn fibril injected cohorts, mice injected in the white matter rich IC area (Cohort 4) display higher (but variable) astrocytosis than in mice injected in the $\mathrm{CPu}$ (Cohort 6) (Fig. 7b, Additional file 6: Figure S6). Surprisingly, in spite of the presence of $\alpha$ Syn pathology, microgliosis was significantly downregulated in 


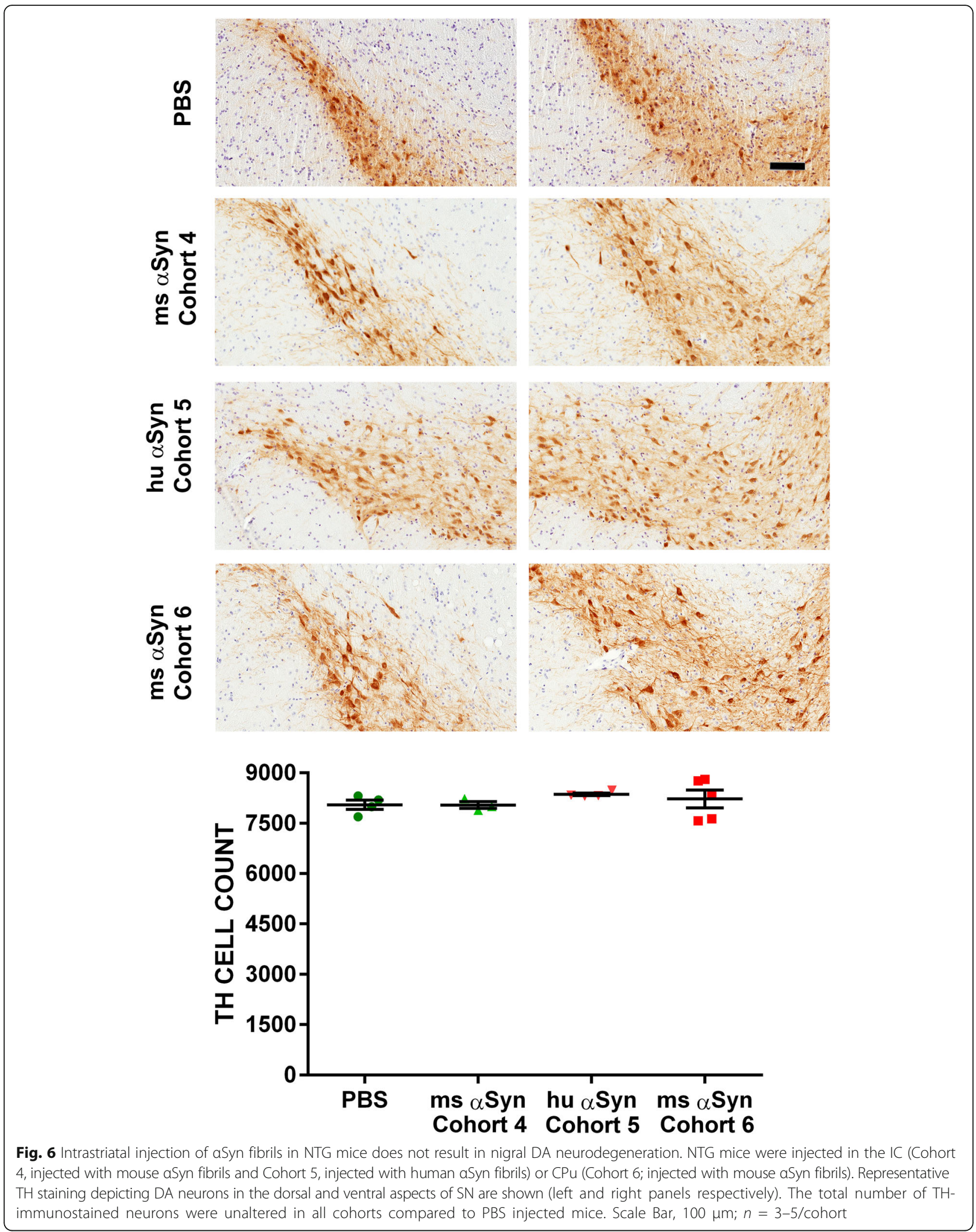




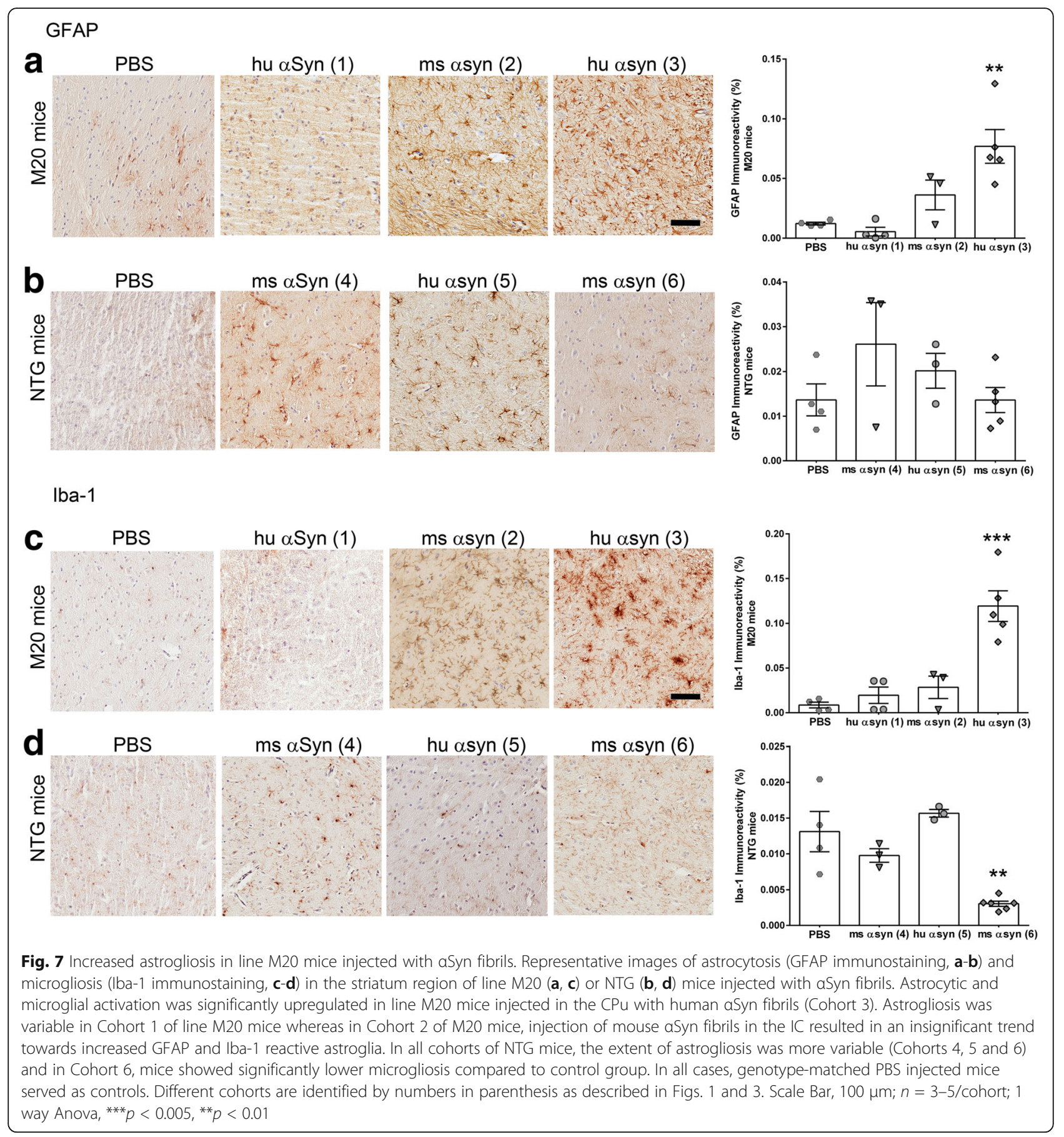

the striatum, hippocampus and entorhinal cortex of NTG mice injected with $\mathrm{ms} \alpha \mathrm{Syn}$ fibrils in the $\mathrm{CPu}$ (Cohort 6; Fig. 7d, Additional file 6: Figure S6).

\section{Induction of robust aSyn pathology within nigral astrocytes but not TH neurons in M20 mice}

In $\alpha$-synucleinopathies, glial $\alpha$ Syn pathology is posited to contribute to progression of the disease and may be directly associated with DA neurodegeneration [38]. Therefore, we next investigated the localization of pSer129- $\alpha$ Syn pathology in glial cells and TH-immunopositive nigral DA neurons in M20 mice that showed frank nigral neurodegeneration (Cohort 1) (Fig. 8a) compared to M20 mice with no DA degeneration (Cohort 3) (Fig. 8b). In both these cohorts, which had widespread $\alpha$ Syn pathology and astrocytosis but differential DA neurodegeneration in the $\mathrm{SN}$, we rarely observed any TH-resident pathological $\alpha$ Syn inclusions (Fig. 8a-b, Additional file 4: Figure S4B-C). 


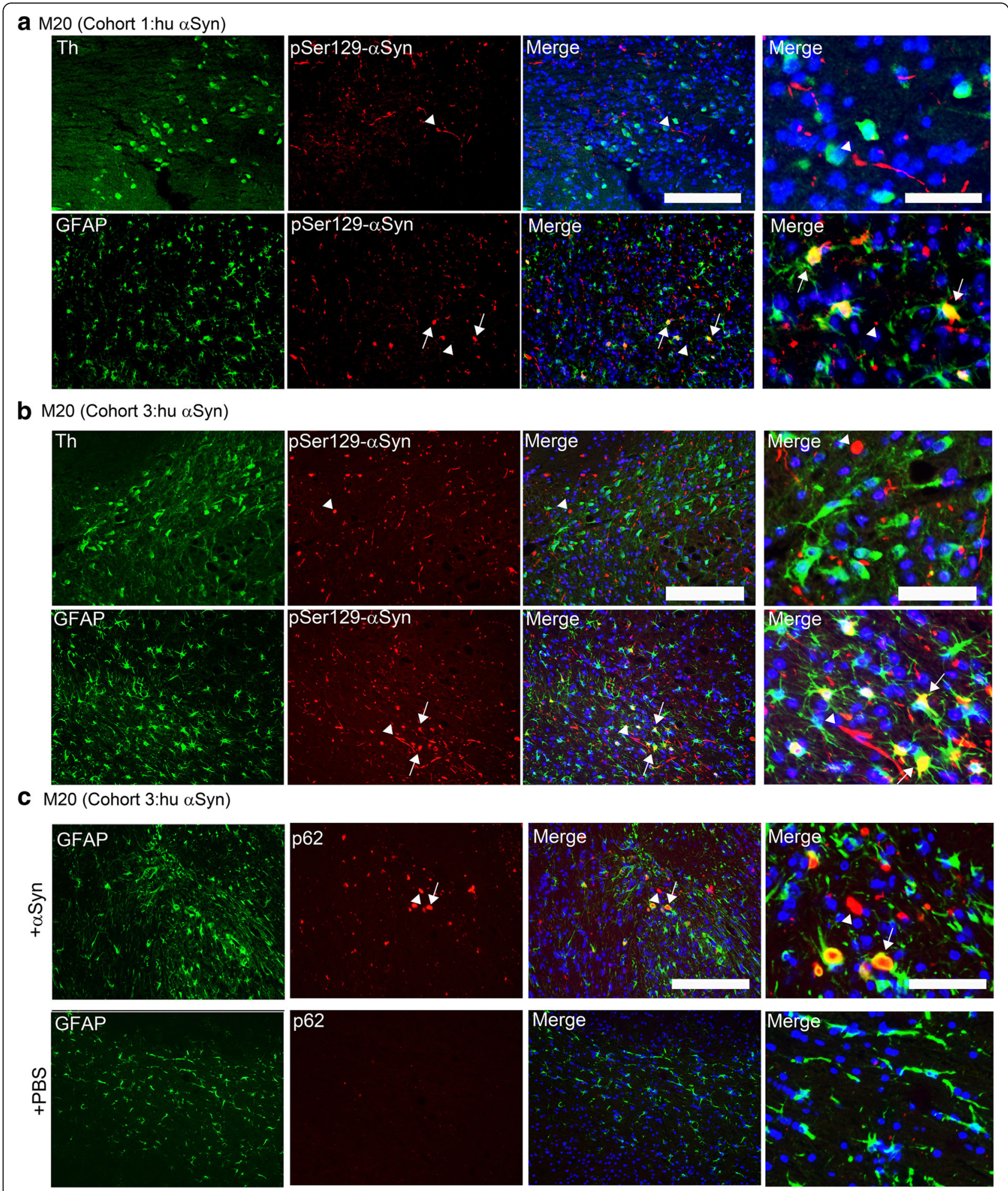

Fig. 8 (See legend on next page.) 
(See figure on previous page.)

Fig. 8 aSyn aggregates preferentially co-localized within astrocytes but not in SN-resident DA neurons in line M20 mice injected with human WT aSyn fibrils. Representative immunofluorescence staining showing co-localization of pSer129 immunoreactive aSyn pathology (red) in the $\mathrm{TH}$ immunopositive DA neurons (green) or GFAP (green) immunopositive astrocytes in the SN region of human aSyn fibril injected M20 mice. In both cohorts of M20 mice injected in the IC or the CPu (a-b: Cohorts 1 and 3 respectively), astrocytes laden with pSer129-aSyn were present in abundance (arrows) while none of these LB type inclusions were identified within the TH-immunopositive DA neurons. Additionally, many cell body inclusions or neurites were present in populations that were not immunopositive for TH (arrowheads). Of note, the astrocytes with resident aSyn pathology resemble hypermorphic reactive state and co-localized with p62, an indicator of decreased autophagic flux (c). PBS injected mice represents the control mice (c). Cell nuclei were stained with DAPI (blue). The 3-color merged panel has been magnified (right panel) to visualize the localization of

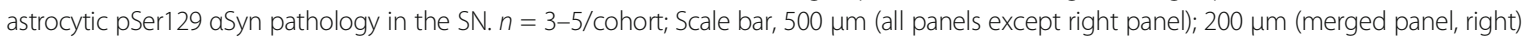

Interestingly, a copious amount of pSer129- $\alpha$ Syn pathology was resident within the GFAP-immunopositive astrocytes in the $\mathrm{SN}$ in both these cohorts (Fig. 8a-b). We next tested whether astrocytic inclusion pathology was associated with autophagic alterations. Since p62 accumulates when autophagy is inhibited, and decreased levels can be observed when autophagy is induced, p62 may be used as a marker to study autophagic flux [39]. We noticed that these astrocytic inclusions were indeed immunopositive for p62, a cellular marker indicating inhibition of autophagy (Fig. 8c).

In Cohort 3, astrocyte resident pSer129- $\alpha$ Syn pathology was also observed in several other brain areas that had induced $\alpha$ Syn pathology, such as ventral midbrain, hippocampus and cortex in these mice (Additional file 7: Figure S7b). We also observed a similar distribution of astrocytic pSer129- $\alpha$ Syn pathology in Cohort 1 of M20 mice injected with human $\alpha$ Syn fibrils, though individual mice in this cohort showed variable induction of astrogliosis (Additional file 7: Figure S7A). In the NTG cohorts displaying induced $\alpha$ Syn pathology (Cohorts 4 and 6 ), we did not observe any astrocytic $\alpha$ Syn pathology in the ventral midbrain, entorhinal cortex or hippocampus (Additional file 8: Figure S8A-B).

\section{Discussion}

Templated conformational alterations in $\alpha$ Syn has been shown to induce LB-like pathology in mice, suggesting that this maybe a significant disease mechanism in human $\alpha$-synucleinopathies [7-10]. While some reports have indicated that induced $\alpha$ Syn pathology spreads along neuroanatomic connections in a prionoid fashion $[18,20,24-26,40]$, we and others have previously reported that propagation of seeded $\alpha$ Syn pathology in mice can follow atypical or non-prionoid characteristics $[17,21,41,42]$. Here, using human WT $\alpha$ Syn transgenic mice (M20) and NTG mice, we show that 1) injection of $\alpha$ Syn aggregates into two different areas of striatum results in widespread $\alpha$ Syn inclusion pathology in M20 mice, irrespective of neuroanatomic connectivity; 2) templated $\alpha$ Syn pathology following intra-striatal injection is not transmitted to DA neurons and causes moderate to no degeneration in DA neurons; 3) induction of $\alpha$ Syn pathology can be an inefficient process and spares the SN-resident $\mathrm{TH}$-immunopositive neurons in NTG mice; and 4) $\alpha$ Syn laden astrocytes were readily observed in brain regions of M20 mice with robust $\alpha$ Syn pathology, suggesting that non-neuronal cells can also contribute to the dissemination of $\alpha$ Syn pathology. Overall, our observations indicate that, in addition to inter-neuronal transfer of seeded $\alpha$ Syn pathology along anatomic connections, simple diffusion or glia-mediated regional transfer may also affect the extent and distribution of pathologies in mouse models of $\alpha$-synucleinopathies. In our study, a significant proportion of $\alpha$ Syn pathological inclusions induced by the administration of exogenous $\alpha$ Syn fibrils were localized within astrocytes throughout the CNS, in stark comparison to other published studies that have shown minimal glial involvement $[18,26]$. It is possible that this unique property of our $\alpha$ Syn preparations along with potential maturation of $\alpha$ Syn pathology within the astroglia may generate unique $\alpha$ Syn conformers with distinctive strain-like properties that are preferentially transmitted via glial cells relative to direct inter-neuronal transfer. Induction of $\alpha$-synucleinopathy by such astrocyte-discriminative $\alpha$ Syn conformers could be used to mechanistically understand the disease etiology in $\alpha$-synucleinopathies with massive glial involvement, such as in multiple system atrophy $[43,44]$. Whether the $\alpha$ Syn fibrils used in our studies indeed possess a preference for enhanced glial transmission relevant to disease pathogenesis in distinct spectra of $\alpha$ synucleinopathies and how this impacts the progression and outcome of different subtypes of $\alpha$-synucleinopathies will be examined in future studies.

\section{Critical parameters that govern dissemination of aSyn seeds: concept of endogenous barriers}

In the prion field, permissive transmission depends on overcoming the species barrier, which is determined by a range of possible conformers of a particular prion, its sequence, as well as its interaction with cellular co-factors such as chaperones [45-47]. One such endogenous 'barrier' relevant to $\alpha$-synucleinopathies may be the subtle differences in the sequence of mouse and human $\alpha$ Syn (7/140 amino acids difference) [48] or their differential interactions with cellular co-factors. Based on this premise, mouse and human $\alpha$ Syn may have differential abilities in recruiting endogenous $\alpha$ Syn into pathological aggregates [26]. In support of this theory, we observed 
that in NTG mice, while mouse $\alpha$ Syn aggregates resulted in induction of $\alpha$ Syn pathology, human $\alpha$ Syn fibrils were ineffective. Therefore, it is likely that a 'species barrier' may determine the structural templating of $\alpha$ Syn and its dissemination in the brain. However, this notion is inconsistent with previous observations in NTG C57BL/ $6 \mathrm{~J}$ mice that intra-nigral injections of human or mouse $\alpha$ Syn aggregates result in identical patterns of pSer129$\alpha$ Syn pathology [25]. Additionally, we found that the templated induction of pathological $\alpha$ Syn by mouse $\alpha$ Syn fibrils is an inefficient process in NTG mice compared to M20 mice. Since exogenous mouse $\alpha$ Syn aggregates do not necessarily recruit endogenous $\alpha$ Syn readily into pathological aggregates, this data suggests that the induction of $\alpha$ Syn pathology is a non-stochastic process dependent on the overall threshold barrier of $\alpha$ Syn protein. Therefore, it is possible that endogenous barriers such as a thresholding effect may regulate the induction and prionoid dissemination of $\alpha$ Syn pathology.

The 'species barrier' concept that can help explain why human WT $\alpha$ Syn fibrils are inefficient in seeding NTG mice is supported by the fact that there are sequence differences between human and mouse $\alpha$ Syn, albeit only 7 amino acids [48]. Interestingly, one of these alterations is an Ala in human $\alpha$ Syn compared to a Thr in mouse $\alpha$ Syn at residue 53 , thus, mouse $\alpha$ Syn intrinsically has the Ala53Thr substitution that cause disease in human. In vitro mouse $\alpha$ Syn has a greater propensity to fibrilize into amyloid than human $\alpha$ Syn, akin to AlaThr53 human $\alpha$ Syn [49]. Although both mouse and human $\alpha$ Syn fibrils can cross-seed monomers of each other to polymerize into fibrils, homotypic seeding is usually more efficient in vitro [14]. Similarly, they both can initiate the aggregation of each other in vivo, but again homotypic seeding is more efficient [14]. However, as shown in extensive studies comparing the influences of amino acid alterations in mouse and human $\alpha$ Syn on the seeded-induction of aggregation, differences observed by in vitro cross-seeding do not always directly correlate with in vivo seeding efficiency [14]. The seeded induction of $\alpha$ Syn aggregation in vivo can be influenced by many differential factors unique to the $\alpha$ Syn seeds including cellular uptake, aggregate stability and cellular binding partners (eg. other proteins and lipids), in addition to subtle differences in the compatibility of unique conformers in initiating the recruitment and aggregation of intrinsic $\alpha$ Syn.

Mechanisms of de novo emergence of prions are still elusive. The aggregation of classical prions has been determined to be a non-stochastic process, whereby threshold of the prion protein determines the efficiency of prionoid transformation and propagation. Indeed, a criterion for prions is that these are formed more efficiently upon over-expression of the native protein. This was reported in the case of SUP35 and URE2 genes, where overproduction of each of these genes induce de novo formation of the respective prions [50, 51]. Indeed, in our present study as well as in previous studies, we have observed that templated induction of $\alpha$ Syn pathology is more efficient in mice overexpressing human $\alpha$ Syn than NTG mice $[17,23]$. This suggests similarities between formation of classical prions and $\alpha$ Syn prionoid species. Overall, our study shows that the efficiency of induction of $\alpha$ Syn aggregation depends on the amount on available $\alpha$ Syn protein in the cell, suggesting that threshold of transgenic protein levels may be a determining factor for ensuring efficient prionoid induction of $\alpha$ Syn pathology.

In this present study and earlier studies [17], we have ascertained that M20 mice injected with $\alpha$ Syn aggregates show dramatic induction of astrogliosis and microgliosis. In sharp contrast to the observations by Rey et al. [26], we observed copious amounts of $\alpha$ Syn pathology co-localized with astrocytes, irrespective of the area of injection. This implies that, in addition to transneuronal transport, astrocytes and possibly other immune cells may also play key roles in the dissemination of pathological $\alpha$ Syn seeds. This has future therapeutic implications as glial cells can effectively act to reduce interneuronal transmission and more importantly clear extracellular $\alpha$ Syn seeds (reviewed in [52]). Indeed, it has been shown that both astrocytes and microglia can internalize and effectively degrade $\alpha$ Syn aggregates [53-56]. Collectively, these data suggest that glial cells that normally do not express or express very low levels of $\alpha$ Syn are not prone to seeding in some settings and this may play an important role in creating an endogenous barrier to the prionoid propagation of $\alpha$ Syn.

\section{Does trans-neuronal propagation of templated aSyn pathology cause DA neurodegeneration?}

The etiology of DA neurodegeneration in the $\mathrm{SN}$ of patients with LB diseases remain unknown. One theory is that trans-neuronal transmission of seeded $\alpha$ Syn pathology along the neuroanatomically connected nigro-striatal pathway causes significant DA neuronal death $[18,20,24]$. However, in our study, we observed only a $20-25 \%$ DA neurodegeneration in M20 mice following injection into the IC with either mouse or human $\alpha$ Syn fibrils. No DA neurodegeneration was noted in NTG mice or in M20 mice injected into the $\mathrm{CPu}$, an area that is directly linked to the SN. Additionally, we were intrigued by our observations that DA neurons were impervious to seeded $\alpha$ Syn pathology in both NTG and M20 mice. We reasoned that this observation can be attributed to multiple complex scenarios such as (1) an initial wave of pathological $\alpha$ Syn inclusion pathology lead to DA neurodegeneration followed by astrocytic engulfment of released materials or (2) astrocytes are able to engulf extracellular $\alpha$ Syn directly during the templated induction and dissemination process [38]. In an effort to localize seeded $\alpha$ Syn pathology in the SN, 
we conducted immunofluorescent co-localization studies using antibodies against non-neuronal cells and found that a majority of these inclusions are present in astrocytes, but not in the nigral TH-immunopositive DA neurons. Since we did not observe any significant nigral DA neurodegeneration in some of these mice (Cohort 3 of M20 mice), our observations suggest that astrocytes likely engulf and scavenge pathological $\alpha$ Syn during the propagation process. Indeed, this is consistent with observations that even direct intra-nigral injection of $\alpha$ Syn aggregates does not necessarily cause nigral DA neurodegeneration $[20,25]$ but would be contrary to observations from other groups $[18,24]$. Interestingly, whether glial cells, such as astrocytes, can have a disease modifying effect in $\alpha$ synucleinopathies by acting as $\alpha$ Syn scavengers or as unwitting vehicles that aid in dissemination of $\alpha$ Syn, remains to be investigated.

\section{Conclusions}

Multiple independent reports, including this present study, show that $\alpha$ Syn aggregates display prionoid characteristics. Additionally, we show that contrary to expected routes of transmissibility exclusively following neuroanatomic connectivity, prionoid $\alpha$ Syn can be widely disseminated throughout the brain by various cellular networks - neurons as well as astrocytes. Therefore, our current findings, when aligned with the present literature, suggest that the mechanism influencing prionoid propagation of $\alpha$ Syn are complex and not always predictable by direct interneuronal connectivity. In fact, glial transmission of $\alpha \mathrm{Syn}$ may also have a major impact on the pathological outcome in $\alpha$-synucleinopathies. These findings are similar to disease pathogenesis by classical prion protein, where different strains of misfolded prions can have contextually-dependent transmission properties in the neuraxis [15, 16, 47]. Importantly, these properties open up potential therapeutic opportunities targeting such extracellular transfer of $\alpha$ Syn by utilizing endogenous immune and non-immune barriers.

\section{Additional file}

Additional file 1: Figure S1. Transmission EM images of aSyn fibrils. Recombinant WT aSyn fibrils (human or mouse) were sonicated and analyzed by EM following uranyl acetate staining. Scale bar, $100 \mathrm{~nm}$.

Additional file 2: Figure S2. Robust aSyn inclusion pathology evident in the brains of M20 mice (Cohorts 1,2 and 3). Robust aSyn inclusion pathology was observed in areas of the brain distal from the injection site such as motor cortex, brainstem, spinal cord and SN of M20 mice injected with aSyn fibrils (A, B, C: Cohorts 1, 2 and 3 respectively). aSyn pathology was identified using pSer129-aSyn antibodies (81A and EP1536Y), Syn506 antibody and p62/Sqstm1 antibody. Both perikaryal (arrowhead) and neuritic (arrow) aSyn pathology was observed. Scale Bar, $100 \mu \mathrm{m} ; n=3-5$ mice/group.

Additional file 3: Figure S3. Robust aSyn inclusion pathology evident in the ependymal cells lining the ventricles of M20 mice (Cohorts 1 and
3). M20 mice injected with human aSyn fibrils (Cohorts 1 and 3) show robust induction of aSyn pathology in the ependymal cells lining the lateral ventricles. aSyn pathology was identified using pSer129-aSyn antibodies (81A and EP1536Y), Syn506 antibody and p62/Sqstm1 antibody. The right panel shows a magnified image of p62-immunopositive ependymal cells. None of the NTG mice injected with aSyn fibrils showed any aSyn pathology in these cells; representative images from NTG Cohort 6 is shown as an example. Hu, human; ms, mouse. $n=3-6 /$ cohort; scale bar, $100 \mu \mathrm{m}$ (all panels except right panel); $50 \mu \mathrm{m}$ (right panel).

Additional file 4: Figure S4. aSyn pathology was not detected in THimmunopositive DA neurons in M20 or NTG mice injected with aSyn fibrils in the striatum. Representative images showing that pSer129-aSyn inclusion pathology (red, arrows) was not localized within nigral TH-immunopositive DA neurons (green) in any of the M20 (Cohorts 2 and 3, A and B respectively) or NTG (Cohorts 4 and 6, D and E respectively) mice injected with aSyn fibrils (A-B). Few aSyn inclusions were observed in the striatal neuronal cell bodies embedded within the TH-positive terminals of M20 mice injected with human aSyn fibrils in the CPu (C). Cell nuclei were stained with DAPI (blue). The 3-color merged panel has been magnified (right panel) to visualize the localization of pSer129 aSyn inclusions in the SN. NTG mice injected with human aSyn fibrils (Cohort 5) is not shown as this cohort had no aSyn inclusion pathology. Numbers in parenthesis denote cohort number as identified in Figs. 1 and 3. Hu, human; ms, mouse. $n=3-6 /$ cohort; Scale bar, $500 \mu \mathrm{m}$ (all panels except right panel); $200 \mu \mathrm{m}$ (merged panel, right).

Additional file 5: Figure S5. Gliosis levels in forebrain areas of line M20 mice injected with human or mouse aSyn fibrils in the striatum. Representative images of astrocytosis (GFAP immunostaining) and microgliosis (lba-1 immunostaining) in the hippocampus and entorhinal cortex (En. Cortex) of line M20 mice injected with aSyn fibrils in the IC (Cohorts 1 and 2) or CPu (Cohort 3). Though there was an overall trend towards higher astrocytic and microglial burden in M20 mice injected with aSyn fibrils which would be co-incident with aSyn inclusion pathology present in these brain areas, there seemed to be individual variability in astroglial numbers within each group. In all cases, PBS injected mice (genotype-matched) served as controls. Different cohorts are identified by numbers in parenthesis on top of corresponding panel. Hu, human; ms, mouse. Scale bar, $100 \mu \mathrm{m} ; n=3-5 /$ cohort; 1 way Anova.

Additional file 6: Figure S6. Gliosis levels in forebrains of NTG mice injected with aSyn fibrils in the striatum. Representative images of astrocytosis (GFAP immunostaining) and microgliosis (Iba-1

immunostaining) in the hippocampus and entorhinal cortex (En. Cortex) of NTG mice injected with WT aSyn fibrils in the IC (Cohorts 4 and 5) or $\mathrm{CPu}$ (Cohort 6). No significant alterations in GFAP staining was observed in any of the cohorts. Increased microgliosis was observed in the entorhinal cortex of NTG mice injected with mouse aSyn fibrils in the IC $\left({ }^{*} p<0.05\right)$ but not in the hippocampus of these mice. Strikingly, dampening of microgliosis was observed in forebrain areas of mice injected with human aSyn (Cohort 5; hippocampus, ${ }^{*} p<0.05$; entorhinal cortex, $p>0.05$ ) as well as in the hippocampus and cortex of NTG mice injected with mouse aSyn fibrils (Cohort $6,{ }^{* *} p<0.01$ ). In all cases, PBS injected mice (genotype-matched) served as controls. Different cohorts are identified by numbers in parenthesis on top of panel. Hu, human; ms, mouse. Scale bar, $100 \mu \mathrm{m} ; n=3-6 /$ cohort; 1 way Anova, ${ }^{*} p<0.05$, ** $p<0.01$

Additional file 7: Figure S7. Astrocytic aSyn inclusions were abundant in midbrain and forebrain areas of line M20 mice injected with human aSyn fibrils (Cohorts 1 and 3). Representative immunofluorescence staining showing co-localization of pSer129 immunoreactive aSyn pathology (red) within the GFAP immunopositive astrocytes (green) in the ventral midbrain, hippocampus and motor cortex of human aSyn fibril injected M20 mice. In both cohorts (1 and 3) of these M20 mice, astrocytes laden with pSer129-aSyn were present in abundance (arrows). Additionally, several LB type inclusions or neurites (arrowheads) were also present in cells that were not immunopositive for GFAP. Cell nuclei were stained with DAPI (blue). The 3-color merged panel has been magnified (right panel) to visualize the localization of astrocytic pSer129 aSyn. Hu, human; ms, mouse. $n=3-5 /$ cohort; Scale bar, $500 \mu \mathrm{m}$ (all panels except right panel); $200 \mu \mathrm{m}$ (merged panel, right). 
Additional file 8: Figure S8. Astrocytic aSyn inclusions were absent in midbrain and forebrain areas of NTG mice injected with mouse aSyn fibrils (Cohorts 4 and 6). Representative immunofluorescence staining showing that pSer129 immunoreactive aSyn pathology (red; A-B) does not colocalize within the GFAP immunopositive astrocytes (green; A-B) in the ventral midbrain, hippocampus and motor cortex of mouse aSyn fibril injected NTG mice (Cohorts 4 and 6). Of note, most of these mice have low numbers of pSer129-aSyn pathology overall. Cell nuclei were stained with DAPI (blue). The 3-color merged panel has been magnified (right panel) to visualize the localization of pSer129 aSyn. Hu, human; ms, mouse. $n=3-6 /$ cohort; Scale bar, $500 \mu \mathrm{m}$ (all panels except right panel); $200 \mu \mathrm{m}$ (merged panel, right). (PDF $17097 \mathrm{~kb}$ )

\section{Abbreviations}

CPu: caudate putamen; DA: dopaminergic; EM: electron microscopy; GFAP: glial fibrillary acidic protein; Iba-1: ionized calcium-binding adapter molecule 1; IC: internal capsule; LB: Lewy body; NTG: nontransgenic; pSer129: aSyn phosphorylated on Serine 129; SN: substantia nigra; Sqstm1: Sequestosome1; TH: Tyrosine Hydroxylase; aSyn: a-synuclein

\section{Acknowledgements}

Not Applicable.

\section{Funding}

This work was supported by grants from the National Parkinson Foundation (NPF-UN203) and NIH/NINDS (NS089622). Publication of this article was funded in part by the University of Florida Open Access Publishing Fund. The authors declare no competing financial interests.

\section{Availability of data and materials}

The datasets supporting the conclusions of this article are included within the article and its additional files.

\section{Authors' contributions}

PC and BG conceived and coordinated the study, analyzed the data and wrote the manuscript; PC performed mouse injections; ZS performed immunostaining, drafted images for publication and participated in data analysis; MMB and VH performed tissue harvesting and immunostaining; NJR performed electron microscopy; TEG participated in data interpretation. All authors read and approved the final manuscript.

\section{Competing interests}

None of the authors have any competing interests in the manuscript

\section{Consent for publication}

Not applicable.

\section{Ethics approval and consent to participate}

All animal experiments were carried out in accordance with the University of Florida IACUC for the care and use of laboratory animals.

\section{Publisher's Note}

Springer Nature remains neutral with regard to jurisdictional claims in published maps and institutional affiliations.

\section{Author details}

'Department of Neuroscience, University of Florida, 1275 Center Drive, PO Box 100159, Gainesville, FL 32610, USA. ${ }^{2}$ Center for Translational Research in Neurodegenerative Disease, University of Florida, Gainesville, FL 32610, USA. ${ }^{3}$ McKnight Brain Institute, University of Florida, Gainesville, FL 32610, USA. ${ }^{4}$ Current address: Department of Neuroscience, Mayo Clinic, Jacksonville, FL -32224, USA.

Received: 8 February 2017 Accepted: 11 May 2017 Published online: 29 May 2017

\section{References}

1. Waxman EA, Giasson BI. Molecular mechanisms of alpha-synuclein neurodegeneration. Biochim Biophys Acta. 2009;1792(7):616-24.
2. Goedert M, Spillantini MG, Del Tredici K, Braak H. 100 years of Lewy pathology. Nat Rev Neurol. 2013;9(1):13-24.

3. Cookson MR. The biochemistry of Parkinson's disease. Annu Rev Biochem. 2005;74:29-52.

4. Anderson JP, Walker DE, Goldstein JM, de Laat R, Banducci K, Caccavello RJ, Barbour R, Huang J, Kling K, Lee M, et al. Phosphorylation of ser-129 is the dominant pathological modification of alpha-synuclein in familial and sporadic Lewy body disease. J Biol Chem. 2006;281(40):29739-52.

5. Waxman EA, Giasson BI. Specificity and regulation of casein kinase-mediated phosphorylation of alpha-synuclein. J Neuropathol Exp Neurol. 2008;67(5):402-16.

6. Fujiwara H, Hasegawa M, Dohmae N, Kawashima A, Masliah E, Goldberg MS, Shen J, Takio K, Iwatsubo T. alpha-Synuclein is phosphorylated in synucleinopathy lesions. Nat Cell Biol. 2002;4(2):160-4.

7. Uchihara T, Giasson BI. Propagation of alpha-synuclein pathology: hypotheses, discoveries, and yet unresolved questions from experimental and human brain studies. Acta Neuropathol. 2016;131(1):49-73.

8. Guo JL, Lee VM. Cell-to-cell transmission of pathogenic proteins in neurodegenerative diseases. Nat Med. 2014;20(2):130-8.

9. Goedert $\mathrm{M}$, Clavaguera F, Tolnay $\mathrm{M}$. The propagation of prion-like protein inclusions in neurodegenerative diseases. Trends Neurosci. 2010;33(7):317-25.

10. Goedert M, Masuda-Suzukake M, Falcon B. Like prions: the propagation of aggregated tau and alpha-synuclein in neurodegeneration. Brain. 2016; 140(Pt 2):266-78.

11. Sacino AN, Thomas MA, Ceballos-Diaz C, Cruz PE, Rosario AM, Lewis J, Giasson $\mathrm{BI}$, Golde TE. Conformational templating of alpha-synuclein aggregates in neuronal-glial cultures. Mol Neurodegener. 2013;8:17.

12. Waxman EA, Giasson BI. A novel, high-efficiency cellular model of fibrillar alpha-synuclein inclusions and the examination of mutations that inhibit amyloid formation. J Neurochem. 2010;113(2):374-88.

13. Luk KC, Song C, O'Brien P, Stieber A, Branch JR, Brunden KR, Trojanowski JQ, Lee VM. Exogenous alpha-synuclein fibrils seed the formation of Lewy body-like intracellular inclusions in cultured cells. Proc Natl Acad Sci U S A. 2009;106(47):20051-6.

14. Luk KC, Covell DJ, Kehm VM, Zhang B, Song IY, Byrne MD, Pitkin RM, Decker SC, Trojanowski JQ, Lee VM. Molecular and biological compatibility with host alpha-Synuclein influences fibril Pathogenicity. Cell Rep. 2016;16(12): 3373-87.

15. Eisenberg $D$, Jucker $M$. The amyloid state of proteins in human diseases. Cell. 2012;148(6):1188-203.

16. Aguzzi A, Heikenwalder M, Polymenidou M. Insights into prion strains and neurotoxicity. Nat Rev Mol Cell Biol. 2007;8(7):552-61.

17. Sacino AN, Brooks M, McKinney AB, Thomas MA, Shaw G, Golde TE, Giasson BI. Brain injection of alpha-Synuclein induces multiple Proteinopathies, Gliosis, and a neuronal injury marker. J Neurosci. 2014;34(37):12368-78.

18. Luk KC, Kehm VM, Zhang B, O'Brien P, Trojanowski JQ, Lee VM. Intracerebral inoculation of pathological alpha-synuclein initiates a rapidly progressive neurodegenerative alpha-synucleinopathy in mice. J Exp Med. 2012;209(5): 975-86.

19. Breid S, Bernis ME, Babila JT, Garza MC, Wille H, Tamguney G. Neuroinvasion of alpha-Synuclein Prionoids after Intraperitoneal and Intraglossal inoculation. J Virol. 2016;90(20):9182-93.

20. Peelaerts W, Bousset L, Van der Perren A, Moskalyuk A, Pulizzi R, Giugliano M, Van den Haute C, Melki R, Baekelandt V. alpha-Synuclein strains cause distinct synucleinopathies after local and systemic administration. Nature. 2015;522(7556):340-4.

21. Sacino AN, Brooks M, Thomas MA, McKinney AB, Lee S, Regenhardt RW, McGarvey NH, Ayers Jl, Notterpek L, Borchelt DR, et al. Intramuscular injection of alpha-synuclein induces CNS alpha-synuclein pathology and a rapid-onset motor phenotype in transgenic mice. Proc Natl Acad Sci U S A. 2014; 111(29):10732-7.

22. Ayers JI, Brooks MM, Rutherford NJ, Howard JK, Sorrentino ZA, Riffe CJ, Giasson BI. Robust central nervous system pathology in transgenic mice following peripheral injection of alpha-Synuclein fibrils. J Virol. 2017;91(2):pii: e02095-16.

23. Sacino AN, Brooks M, Thomas MA, McKinney AB, McGarvey NH, Rutherford NJ, Ceballos-Diaz C, Robertson J, Golde TE, Giasson Bl. Amyloidogenic alphasynuclein seeds do not invariably induce rapid, widespread pathology in mice. Acta Neuropathol. 2014;127(5):645-65.

24. Luk KC, Kehm V, Carroll J, Zhang B, O'Brien P, Trojanowski JQ, Lee VM. Pathological alpha-synuclein transmission initiates Parkinson-like neurodegeneration in nontransgenic mice. Science. 2012;338(6109):949-53. 
25. Masuda-Suzukake M, Nonaka T, Hosokawa M, Oikawa T, Arai T, Akiyama H, Mann DM, Hasegawa M. Prion-like spreading of pathological alpha-synuclein in brain. Brain. 2013;136(Pt 4):1128-38.

26. Rey NL, Steiner JA, Maroof N, Luk KC, Madaj Z, Trojanowski JQ, Lee VM, Brundin P. Widespread transneuronal propagation of alpha-synucleinopathy triggered in olfactory bulb mimics prodromal Parkinson's disease. J Exp Med. 2016;213(9):1759-78.

27. Prusiner SB, Woerman AL, Mordes DA, Watts JC, Rampersaud R, Berry DB, Patel S, Oehler A, Lowe JK, Kravitz SN, et al. Evidence for alpha-synuclein prions causing multiple system atrophy in humans with parkinsonism. Proc Natl Acad Sci U S A. 2015;112(38):E5308-17.

28. Guo JL, Covell DJ, Daniels JP, Iba M, Stieber A, Zhang B, Riddle DM, Kwong LK, Xu Y, Trojanowski JQ, et al. Distinct alpha-synuclein strains differentially promote tau inclusions in neurons. Cell. 2013;154(1):103-17.

29. Mastrianni JA. The genetics of prion diseases. Genet Med. 2010;12(4):187-95.

30. Osterberg VR, Spinelli KJ, Weston LJ, Luk KC, Woltjer RL, Unni VK. Progressive aggregation of alpha-synuclein and selective degeneration of lewy inclusion-bearing neurons in a mouse model of parkinsonism. Cell Rep. 2015;10(8):1252-60.

31. Dawson TM, Dawson VL. Molecular pathways of neurodegeneration in Parkinson's disease. Science. 2003;302(5646):819-22.

32. Giasson BI, Duda JE, Quinn SM, Zhang B, Trojanowski JQ, Lee VM. Neuronal alpha-synucleinopathy with severe movement disorder in mice expressing A53T human alpha-synuclein. Neuron. 2002;34(4):521-33.

33. Giasson Bl, Murray IV, Trojanowski JQ, Lee VM. A hydrophobic stretch of 12 amino acid residues in the middle of alpha-synuclein is essential for filament assembly. The J Biol Chem. 2001;276(4):2380-6.

34. Waxman EA, Duda JE, Giasson BI. Characterization of antibodies that selectively detect alpha-synuclein in pathological inclusions. Acta Neuropathol. 2008; 116(1):37-46.

35. Kitada T, Tong Y, Gautier CA, Shen J. Absence of nigral degeneration in aged parkin/DJ-1/PINK1 triple knockout mice. J Neurochem. 2009;111(3): 696-702.

36. Watabe-Uchida M, Zhu L, Ogawa SK, Vamanrao A, Uchida N. Whole-brain mapping of direct inputs to midbrain dopamine neurons. Neuron. 2012; 74(5):858-73.

37. Pan WX, Mao T, Dudman JT. Inputs to the dorsal striatum of the mouse reflect the parallel circuit architecture of the forebrain. Front Neuroanat. 2010;4:147.

38. Bruck D, Wenning GK, Stefanova N, Fellner L. Glia and alpha-synuclein in neurodegeneration: a complex interaction. Neurobiol Dis. 2016;85:262-74.

39. Bjorkoy G, Lamark T, Pankiv S, Overvatn A, Brech A, Johansen T. Monitoring autophagic degradation of p62/SQSTM1. Methods Enzymol. 2009;452:181-97.

40. Masuda-Suzukake M, Nonaka T, Hosokawa M, Kubo M, Shimozawa A, Akiyama H, Hasegawa M. Pathological alpha-synuclein propagates through neural networks. Acta Neuropathol Commun. 2014;2:88.

41. Sacino AN, Ayers JI, Brooks MM, Chakrabarty P, Hudson VJ 3rd, Howard JK, Golde TE, Giasson BI, Borchelt DR. Non-prion-type transmission in A53T alpha-synuclein transgenic mice: a normal component of spinal homogenates from naive non-transgenic mice induces robust alpha-synuclein pathology. Acta Neuropathol. 2016;131(1):151-4.

42. Mason DM, Nouraei N, Pant DB, Miner KM, Hutchison DF, Luk KC, Stolz JF, Leak RK. Transmission of alpha-synucleinopathy from olfactory structures deep into the temporal lobe. Mol Neurodegener. 2016;11(1):49.

43. Croisier E, Graeber MB. Glial degeneration and reactive gliosis in alphasynucleinopathies: the emerging concept of primary gliodegeneration. Acta Neuropathol. 2006;112(5):517-30.

44. Fellner $L$, Jellinger KA, Wenning GK, Stefanova N. Glial dysfunction in the pathogenesis of alpha-synucleinopathies: emerging concepts. Acta Neuropathol. 2011;121(6):675-93.

45. Collinge J, Clarke AR. A general model of prion strains and their pathogenicity. Science. 2007;318(5852):930-6.

46. Kushnirov W, Kryndushkin DS, Boguta M, Smirnov VN, Ter-Avanesyan MD. Chaperones that cure yeast artificial [PSI+] and their prion-specific effects. Curr Biol. 2000;10(22):1443-6.

47. Chien P, Weissman JS, DePace AH. Emerging principles of conformationbased prion inheritance. Annu Rev Biochem. 2004;73:617-56.

48. George JM. The synucleins. Genome Biol. 2002;3(1):REVIEWS3002.

49. Rochet JC, Conway KA, Lansbury PT Jr. Inhibition of fibrillization and accumulation of prefibrillar oligomers in mixtures of human and mouse alpha-synuclein. Biochemistry. 2000;39(35):10619-26.
50. Derkatch IL, Chernoff YO, Kushnirov W, Inge-Vechtomov SG, Liebman SW. Genesis and variability of [PSI] prion factors in Saccharomyces cerevisiae. Genetics. 1996;144(4):1375-86.

51. Masison DC, Maddelein ML, Wickner RB. The prion model for [URE3] of yeast: spontaneous generation and requirements for propagation. Proc Natl Acad Sci U S A. 1997;94(23):12503-8.

52. Lee HJ, Bae EJ, Lee SJ. Extracellular alpha-synuclein-a novel and crucial factor in Lewy body diseases. Nat Rev Neurol. 2014;10(2):92-8.

53. Kim C, Ho DH, Suk JE, You S, Michael S, Kang J, Joong Lee S, Masliah E, Hwang D, Lee HJ, et al. Neuron-released oligomeric alpha-synuclein is an endogenous agonist of TLR2 for paracrine activation of microglia. Nat Commun. 2013;4:1562.

54. Lee HJ, Suk JE, Bae EJ, Lee JH, Paik SR, Lee SJ. Assembly-dependent endocytosis and clearance of extracellular alpha-synuclein. Int J Biochem Cell Biol. 2008:40(9):1835-49.

55. Lee HJ, Suk JE, Patrick C, Bae EJ, Cho JH, Rho S, Hwang D, Masliah E, Lee SJ. Direct transfer of alpha-synuclein from neuron to astroglia causes inflammatory responses in synucleinopathies. J Biol Chem. 2010;285(12):9262-72.

56. Stefanova N, Fellner L, Reindl M, Masliah E, Poewe W, Wenning GK. Toll-like receptor 4 promotes alpha-synuclein clearance and survival of nigral dopaminergic neurons. Am J Pathol. 2011;179(2):954-63.

57. Franklin KBJ, Paxinos G. Paxinos and Franklin's the mouse brain in stereotaxic coordinates. fourth ed. Amsterdam: Academic Press, an imprint of Elsevier; 2013

\section{Submit your next manuscript to BioMed Central and we will help you at every step:}

- We accept pre-submission inquiries

- Our selector tool helps you to find the most relevant journal

- We provide round the clock customer support

- Convenient online submission

- Thorough peer review

- Inclusion in PubMed and all major indexing services

- Maximum visibility for your research

Submit your manuscript at www biomedcentral.com/submit 